\title{
La teoría agustiniana de la lluminación en el De Genesi ad litteram (libro XII)
}

El libro XII del De Genesi ad litteram ha tenido un enorme y duradero influjo en el campo de la teología mística. Directamente estudia en él San Agustín los fenómenos extraordinarios de visiones y éxtasis, que aparecen en la Escritura, especialmente el caso de San Pablo arrebatado al tercer cielo ${ }^{1}$. Pero indirectamente el libro es también de gran interés para el filósofo, que descubre en él, aplicadas a un caso concreto y particular, las líneas generales de la teoría agustiniana de la iluminación.

I. Empieza San Agustín por distinguir y descubrir tres géneros de visiones (tria genera visionum).

El primero, corporal (corporale, per corporis sensus), cuyo objeto son los cuerpos presentes: corpora... praesentia videntes in suis formis (nn. 15 y 16 ).

El segundo, espiritual (spirituale, per spiritum), cuyo objeto son las imágenes de los cuerpos ausentes: corpora... absentia cogitantur imaginibus animo impressis (nn. 15 y 16 ).

San Agustín llama, pues, «espiritual» lo que nosotros llamamos

1. "Die Nachwelt ist Augustin fast überschwenglich dankbar geblieben, so sehr, dass sie, was die entwickelte Psychologie betriffit, ihm bedenkenlos wenigstens bis zum einbrechenden Aristotelismus des 13. Jahrhunderts, bis zu Thomas von Aquin gefolgt ist, was aber die Werttafel der Mystik angeht, weit da über hinaus, nämlich wenigstens bis zu Theresia von Jesus und Johannes von Kreuz". M. E. KORGER, "Grundprobleme der augustinischen Erkenntnislehre". Erläutert am beispiel von "De Genesi ad litteram XII": Recherches augustiniennes, vol. II, 1962, p. 34 . 
(imaginario» y su spiritus equivale a nuestra imaginación reproductora y creadora ${ }^{2}$.

Nec illud alterum (genus visionis), quo absentia corpora cogitantur, insinuare difficile est: ipsum quippe coelum et terram, et ea quae in eis videre possumus, etiam in tenebris constituti cogitamus; ubi nihil videntes oculis corporis, animo tamen corporales imagines intuemur, seu veras, sicut ipsa corpora videmus et memoria retinemus; seu fictas, sicut cogitatio formare potuerit. Aliter enim cogitamus Carthaginem quam novimus, aliter Alexandriam quam non novimus" (n. 15).

El tercer género de visión es el intelectual (intellectuale, per contuitum mentis) y su objeto son: eas res ...quae non habent imagines sui similes, quae non sunt quod ipsae (nn. I5 y 16) ${ }^{3}$

San Agustín pone un ejemplo de esta visión intelectual en el conocimiento del amor.

"Dilectio numquid aliter videtur praesens in specie qua est, et aliter absens in aliqua imagine sui simili? Non utique; sed quantum mente cerni potest, ab alio magis, ab alio minus, ipsa cernitur" (n. 15).

Unos capítulos más arriba enumeraba varias de estas realidades que no son cuerpos ni imágenes de cuerpos:

\begin{abstract}
"Substantia quae nullam corporis similitudinem gerit, sicut Deus, sicut ipsa mens hominis, vel intelligentia, vel ratio, sicut virtutes, prudentia, iustitia, caritas, castitas, pietas, et quaecumque aliae sunt, quas intelligendo atque cogitando enumeramus, discernimus, definimus, non utique intuentes lineamenta earum vel colores, aut quomodo sonent, aut quid oleant, aut quid in ore sapiant, aut quid contrectantibus de calore seu frigore, mollitudine seu duritia, lenitate seu asperitate renuntient; sed alia qua dam visione, alia luce, alia rerum evidentia, et ea longe caeteris praestantiore atque certiore" (n. 6).
\end{abstract}

2. Cfr. R. JOLIVET, Dieu soleil des esprits. La doctrine augustinienne de l'illumination (Paris 1934) 203-205.

3. El p oblema que plantea San Agustín en el n. 21, a saber, si toda realidad inteligible es a la vez inteligente (o como él dice intelectual) es de origen plotiniano. Cfr. J. PePIN, "Une curieuse déclaration idéaliste du De Genesi ad litteram de saint Augustin, et ses origines nlotiniennes": Rev Hist Phil Rel 34 (1954) 373-400. De todos modos San Agustin declara que va a dejar de lado el fondo del problema y oue, nor lo gue a la terminologia se refiere, va a tomar intelligibilis e intellectualis como equivalentes. 
Si tenemos presente cuánto le costó a San Agustín separar la noción de realidad y la noción de cuerpo y llegar a concebir la existencia de realidades espirituales, nos explicaremos su insistencia en poner de relieve y en hacer comprensible la existencia de un mundo superior incorpóreo en el que vive el espíritu y en el que se refleja de un modo especial la luz de la Verdad.

El amor, explica San Agustín, tiene realidad, es una substancia, pero no corporal, no puede verse con los ojos, ni representarse (cogitari) con el spiritus. Es una realidad intelectual y sólo puede verse por el entendimiento: sola mente, id est, intellectu cognosci et percipi (n. 22).

De estas realidades intelectuales dice San Agustin que non habent imagines sui similes, quae non sunt quod ipsae (n. I5) y que non sunt imagines rerum, sed res ipsae. Es decir, que cuando conozco el amor, no conozco su imagen, su representación. Estas realidades incorporales las conocemos per praesentiam, non per imagines ${ }^{4}$, sine imaginibus, sicuti sunt, per se ipsa ${ }^{4}$.

Consecuentemente, en la visión intelectual, no puede haber error: intellectualis visio non fallitur.

En la visión corporal cabe el error, cuando se toma por realidad objetiva lo que es mera impresión subjetiva (por ejemplo, el palo en el agua aparece quebrado). También cabe el error en la visión (espiritual), cuando se toma por cuerpo lo que es mera imagen del cuerpo (por ejemplo, en los alucinados).

Pero en la visión intelectual el alma entiende o no entiende, pero propiamente no yerra, no cabe aquí tomar una cosa por otra.

"At vero in illis intelectualibus visis non fallitur (anima); aut enim intelligit, et verum est; aut si verum non est, non intelligit: unde aliud est in his errare quae videt, aliud ideo errare quia non videt" (n. 52) ${ }^{5}$.

2. Despues de haber descrito las tres clases de visiones, establece San Agustín el ordeñ jerấrquico de las mismas.

4. Las tres últimas citas son del libro $\mathrm{x}$ de las Confesiones, nn. 15, 17 y 11 espectivamente.

5. Cfr. n. 29: "Intellectualis visio non fallitur. Aut enim non intelligit, qui aliud opinatur quam est; aut si intelligit, continuo verum est". 
La visión (espiritual» es superior a la visión corporal, que no hace más que presentar los datos sensibles.

"Corporalis visio nulli horum generi praesidet, sed quod per eam sentitur, illi spirituali tamquam praesidenti nuntiatur" (n. 22).

Es de notar, observa San Agustín, que no sólo hay imagen «espiritual» cuando nos representamos un cuerpo ausente, sino también en la misma sensación de un cuerpo presente, sólo que entonces no nos percatamos de la existencia de la imagen.

"Nam cum aliquid oculis cernitur, continuo fit imago eius in spiritu; sed non dignoscitur facta, nisi cum ablatis oculis ab eo quod per oculos videbamus, imaginem eius in animo invenerimus" (n. 22).

En el hombre, por encima del spiritus está el intellectus, que o entiende o investiga el significado del signo sensible presentado por aquél :

"Si anima rationalis est, etiam intellectui nuntiatur, qui et spiritui praesidet, ut si illud quod hauserunt oculi, atque id spiritui, ut eius illic imago fieret, nuntiaverunt, alicuius rei signum est, aut intelligatur continuo quid significet, aut quaeratur; quo niam nec intelligi nec requiri nisi officio mentis potest" (n. 22).

Más adelante, a modo de resumen, vuelve a ordenarse jerárquicamente (habent ordinem suum) las tres visiones: corporal, (cespiritual) e intelectual:

"Praestantior est visio spiritualis quam corporalis, et rursus praestantior intellectualis quam spiritualis" (n. 51).

El valor de cada visión depende de su función y de su grado de independencia, según un principio que puede formularse así: la visión de orden inferior no puede darse (en el hombre, si es un acto humano, consciente) sin la superior; la superior en cambio puede darse sin las inferiores.

(a) La visión corporal no puede darse sin la (espiritual», ¿Razon? Si sólo hubiera contacto del objeto con el sentido del cuerpo y 
no hubiera simultáneamente una imagen del cuerpo en el spiritus, no habría sensación :

"Corporalís (visio) sine spirituali esse non potest; quandoquidem momento eodem quo corpus sensu corporis tangitur, fit etiam in animo tale aliquid, non quod hoc sit, sed quod simile sit; quod si non fieret, nec sensus ille esset, quo ea quae extrinsecus adiacent, sentiuntur" (n. 51).

Lo que ocurre es que sólo nos percatamos de la existencia de la imagen, cuando cesa la sensación externa:

"Non potest itaque fieri visio corporalis, nisi etiam spiritualis simul fiat; sed non discernitur, nisi cum fuerit sensus ablatus a corpore, ut id quod per corpus videbatur, inveniatur in spiritu" ( $n$. 51). ${ }^{6}$.

$Y$ es que, en la concepción agustiniana de la sensación, no es el cuerpo el que siente, sino el alma por el cuerpo:

"Neque enim corpus sentit, sed anima per corpus, quo velut nuntio utitur ad formandum in se ipsa quod extrinsecus nuntiatur" (n. 51).

Lo que este texto solamente insinúa, a saber, que la imagen del cuerpo no es obra del cuerpo, sino del spiritus exclusivamente, está dicho con claridad en un pasaje anterior.

"Eamdem (corporis) imaginem non corpus in spiritu sed ipse spiritus in se ipso facit celeritate mirabili, quae ineffabiliter longe est a corporis tarditate; cuius imago mox ut oculis visum fuerit, in spiritu videntis nullius puncti temporalis interpositione formatur" (n. 33).

Admitir que el cuerpo pueda obrar en el spiritus, siendo así que le es inferior, sería un contrasentido, para un pensador platónico.

"Nec sane putandum est facere aliquid corpus in spiritu, tamquam spiritus corpori facienti, materiae vice subdatur. Omni

6. "En fait la 'vision corporelle' n'est pas, par elle-même, une véritable vision: prise, en quelque sorte, à l'état pur, elle n'est autre chose, comme on l'a vu, qu'une pure passion corporelle: pour qu'il y ait vision réelle, il faut l'intervention du 'spiritus', qui forme les similitudes corporelles". R. JOLIVET, o.c., 159 . 
enim modo praestantior est qui facit, ea re de qua aliquid facit; neque ullo modo spiritu praestantius est corpus; immo perspicuo modo spiritus corpore" (n. 33).

(b) La visión "espiritual» puede darse sin la corporal:

"At vero spiritualis visio etiam sine corporali fieri potest, cum absentium corporum similitudines in spiritu apparent, et finguntur multae pro arbitrio, vel praeter arbitrium demonstantur" (n. 51).

(c) La visión (espiritual) no puede darse (si es un acto humano) sin la intelectual. La intelectual en cambio es independiente de las otras dos y por tanto les es superior.

"Spiritualis visio indiget intellectuali ut diudicetur, intellectualis autem ista spirituali inferiore non indiget; ac per hoc spirituali corporalis, intellectuali autem utraque subiecta est" (n. 51).

3. La noción agustiniana de spiritus, que aparece en este libro, necesita una aclaración.

Spiritus, en sentido estricto (modo proprio) es definido así:

"Vis animae quaedam mente inferior, ubi corporalium rerum similitudines exprimuntur" (n. 20).

Ahora bien, si spiritus es una vis animae; si por tanto no es corporal, sino anímico (o sea espiritual en nuestra terminología), ¿no resulta paradójico hablar de imago corporis in spiritu (n. 33) o de incorporeae similitudines corporum? ${ }^{7}$ 'es comprensible una imagen corporal formada por e impresa en una potencia incorporal?

San Agustín padece en este punto el influjo no suficientemente criticado del pensamiento neoplatónico, especialmente de Porfirio ${ }^{8}$.

El mismo San Agustín, en su obra De Civitate Dei, da a entender de dónde ha tomado, modificándola, su concepción del spiritus. Describe alli el pensamiento de Porfirio y refiere que este pensador

7. Epist 147, 16, 38.

8. Cfr. G. Vereere, L'évolution de lä doctrine du Pneuma du stoïcisme à saint Augustin (Paris-Louvain 1945). También M. E. KroGER, o.c., 3843. 
distingue dos partes en el alma: una intelectual, qua rerum intelligibilium percipitur veritas; y otra espiritual, qua corporalium rerum capiuntur imagines ?.

En rigor, para Plotino y Porfirio el pneuma no es propiamente una parte del alma, sino su envoltorio, que la protege de toda contaminación material, cuando aquella se une con el cuerpo.

Este pneuma que, como un velo, envuelve el alma es una substancia corporal tenue (como la luz o el aire), intermedia entre el alma y el cuerpo ${ }^{10}$.

San Agustín no admite ciertamente esta pneumatología porfiriana. No existe pâra él una realidad intermedia, que no sea alma ni cuerpo. El spiritus agustiniano no es una realidad intermedia, sino una actividad inferior del alma subordinada a la superior e intelectual ${ }^{11}$.

$Y$, sin embargo, quedan en el pensamiento agustiniano, restos de la concepción neoplatónica, inasimilados e inasimilables. San Agustín admite, como hemos visto, entre la substancia corporal (corpus) y la substancia incorpórea (non corpus) una realidad media (no substancial): simile corporis.

"Non absurde neque inconvenienter arbitror spiritualem visionem inter intellectualem et corporalem tanquam medietatem quamdam obtinere. Puto enim non incongruenter medium dici quod corpus quidem non est, sed simile est corporis, inter illud quod vere corpus est et illud quod nec corpus est nec simile corporis" (n. 51) ${ }^{12}$.

9. De civ Dei X, 9, 2 .

10. He aquí "les lignes fondamentales de la pneumatologie de Porphyre: le corps lumineux, qui constitue durant sa vie terrestre l'intermédiaíre entre l'âme el le corps reste uni à l'âme rationnelle même après la mort et partage sa destinée bienheureùse pourvu qu'il soit purifié". G. VerBEKE, o.c., 370 .

11. "Il y a une différence importante entre la pneumatologie de Porphyre et la doctrine augustinienne du spiritus, c'est que ce spiritus est considéré comme une puissance de l'âme, alors que le pneuma de Porphyre est décrit comme une enveloppe psychique: il en résulte que le spiritus d'Augustin, tout en étant subordonné à l'intelligence, fait cependant partie de l'âme immatérielle, tandis que le caractère matériei de ${ }^{\prime}$ enveloppe pneumatique des neóplatoniciens est incontestable". Ibidem, 504.

12. Cfr. n. 16: “Quidquid corpus non est et tamen aliquid est lam 
Ahora bien, la noción de una realidad no corporal semejante a los cuerpos (simile corporis), lo mismo que la noción contraria, que aparece en otros pasajes de la obra ${ }^{13}$, de una realidad corporal (la luz o el aire) semejante al espíritu (spiritui similiora), propiamente hablando, y prescindiendo de posibles significados metafóricos, resulta incomprensible.

4. Hasta aquí ha tratado San Agustín preferentemente de la visión (espiritual). En adelante, va a tratar de la intelectual (nn. $5^{\circ}$ y siguientes).

Aunque en estos textos está hablando San Agustín de la interpretación de visiones o imágenes proféticas, es fácil ver en ellos una aplicación particular de la concepción general agustiniana del conocimiento de la verdad.

Las imagines corporum o las similitudines rerum corporalium en el spiritus son signos cuyo significado desconoce el mismo spiritus: videbantur (signa) in spiritu et nondum intelligebantur (n. 23). El spiritus sólo ve el signo. El intellectus comprende el signo, entiende su significado, «juzga» la verdad de la imagen sensible representada en el spiritus.

"Spiritus informatus est ut videret, mens illuminata ut intelligeret" (n. 22).

"Spiritualis visio indiget intellectuali ut diudicetur" (n. 51).

La mens puede entender y juzgar la verdad del signo, porque está iluminada por Dios, que es la Luz y la Verdad:

"Aliud est ipsum lumen, quo inustratur anima, ut omnia vel in se vel in illo veraciter intellecta conspiciat: nam illud iam iose Deus est" (n. 59).

Supongo conocida, en este trabajo, la teoría de la iluminación ${ }^{14}$

recte spiritus dicitur: et litique non est corpus, quamvis corpori similis sit, imago absentis corporis, nec ille ipse obtutus quo cernitue".

13. De Genesi ad litteram VII, 19, 25; cfr. ibidem, IV, 34, 54; VII, 13 20 ; XII, 16, 32 .

14. He intentado recientemente una sintesis de la misma, desde el punto de vista de la memoria, en un artículo que aparecerá próximamente en Pensamiento, con el título: "El fundamento del conocimiento de la verdad, en San Agustín: la memoria Dei". 
e intento solamente recoger los elementos que de la misma se hallan presentes en el libro XII del De Genesi ad litteram. No me detendré por tanto ahora en exponer el sentido de la iluminación que postula San Agustín para que el entendimiento pueda juzgar y conocer la verdad.

Pero hay una obra, casi contemporánea de este libro XII, que nos permitirá completar la cuestión expuesta. Se trata de la carta 147 , conocida también como tratado breve bajo el título De videndo Deo ${ }^{14}$ bis.

En el capítulo I7, se compara el conocimiento sensible con el intelectual y se concluye: solamente los ojos interiores pueden conocer la verdad y juzgan por tanto a los exteriores:

\begin{abstract}
"Num ergo iis oculis cordis tui, quibus haec omnia vera et certa esse contueris, tibique praesentia invisibiliter cernis atque discernis, ullo modo corporeos oculos comparabis?... Cum ergo interiores oculi iudices sint oculorum exteriorum, isti autem illis quodam oficio nuntiandi et ministerio famulantur, multaque ilij videant quae isti non vident, njhil isti videant, unde non illi tanquam praesides iudicent; quis non illos istis incomparabili aestimatione praeponat? $?^{3 i}(n .4 j)^{15}$.
\end{abstract}

Comenta R. Jolivet: "Les yeux du corps nous apportent des imagen $_{+}$mais ils ne peuvent pas juger de leur vérité. Seul l'esprit est capable de discerner l'intelligible auquel participent les choses dont les sens nous fournissent les images sensibles, et seul à même, par conséquent, de porter un jugement vrai sur ces choses et de s'élever à la science) ${ }^{16}$.

Ahora bien, para que el entendimiento pueda «juzgar» ha de estar iluminado, es decir, ha de conocer de algún modo la norma del juicio, el criterio de la verdad. Es necesaria una luz intelectual para ver la verdad, lo mismo que es necesaria una luz material para ver los cuerpos.

14 bis. Tanto el libro XII como la carta 147 fueron escritos hacia el 413 ó 414.

15. Notemos en el n. 45 la expresión lux iudicans.

16. Dieu soleil des esprits, I. 147. 
"Cum indicas, in nulla te putas, an in aliqua luce versari? Ego enim existimo quod tanta tibi et talia, tam vera, tam clara, tam certa videri sine luce non possunt" (n. 42).

Conocer, para San Agustín, es reconocer. Sólo es posible reconocer aquello que se pre-conoce. Este es, en mi opinión, el sentido íntimo de la iluminación agustiniaña. La luz de Diós y la palabra del Maestro imprimen en la memoria aquellos primeros principios y nociones sin los cuales no hay pensamiento. El espíritu afirma la unidad, la verdad y la bondad del objeto conocido, porque pre-conoce el ser.

5. Si el espíritu, para conocer la verdad, ha de estar iluminado, si Dios es la luz que le ilumina, ¿quiere esto decir que el espíritu humano, cuando conoce la verdad, ve a Dios?

No. Y éste es un lugar claro en el libro XII, para rechazar todo ontologismo en la interpretación de la teoría de la iluminación.

En este mundo, dice San Agustín, conocemos a Dios sólo oscuramente, in aenigmate. Son raros los hombres que, por un don extraordinario, han visto a Dios en esta vida cara a cara, per speciem. La vi sión clara de Dios, in illa specie qua Deus est, es ultramundana, propia de los bienaventurados.

\begin{abstract}
"Ibi videtur claritas Dei... non per aliquam corporaliter vel spiritualiter figuratam significationem tanquam per speculum in aenigmate, sed facie ad faciem..., per speciem scilicet qua est Deus quidquid ipse, quantulumcumque eum mens, quae non est quod ipse, etiam ab omni terrena labe mundata et ab omni corpore et similitudine corporis alienata et abrepta capere potest: a quo peregrinamur mortali et corruptibili onere gravati, quanindiü per fidem ambulamus, non per speciem, et cum hic iuste vivimus" (n. 56) ${ }^{17}$.
\end{abstract}

En este mundo por tanto el espíritu humano no puede ver a Dios. La iluminación divina que San Agustín postula en el conocimiento de la verdad, no significa que el espíritu ve la Luz que es Dios, sino solamente que ve a la luz de Dios. La Luz no podemos contemplarla (intueri) y sin embargo sólo a su luz podemos entender: inde est tamen quidquid intelligit.

17. Véanse también los nn. 54 y 55 . 
"In illo genere intellectualium visorum sunt quae in ipsa anima videntur, velut virtutes quibus vitia sunt contraria... Aliud autem est ipsum lumen, quo illustratur anima, ut omnia vel in se vel in illo veraciter intellecta conspiciat: nam illud iam ipse Deus est, haec autem creatura, quamvis rationalis et intellectualis ad eius imaginem facta, quae cum conatur lumen illud intueri, palpitat infirmitate, et minus valet" (n. 59).

Esta distinción de una Luz en sí y una luz para nosotros aparece también en la carta 147, antes citada. Intenta San Agustín hacer comprender a su corresponsal que Dios es una realidad incorpórea e invisible para los ojos del cuerpo.

Para ello le hace ver primero que hay en el hombre mismo una realidad incorpórea. En efecto, los recuerdos sensibles (la tierra, los astros...) en la memoria no ocupan lugar. Hay además en nuestro es. píritu conocimientos de realidades a todas luces incorporales, como la caridad, el gozo, la paz, etc.

Ahora bien, si el hombre es (también) incorporal, si además de la luz material que ilumina los ojos de su cuerpo para ver las realidades corporales, una luz incorporal ilumina los de su espíritu para conocer aquellas realidades incorporales, jcuánto más incorporal e invisible será Dios, que habita en una luz inaccesible!

"Nam si interior homo noster, quantulacumque imago Dei, non de illo genita, sed ab illo creata, quamvis adhuc renovetur de die in diem, iam tamen in tali luce habitat, quo nullus oculorum corporalium sensus accedit; si ea quae in illa luce cordis oculis inrantur: quanto magis Deus, qui lucem habitat inaccessibilem t,uemur, et discernuntur inter se, et nullis locorum spatiis sepacorporis sensibus, quo nec ipsius nisi mundi potest esse cordis accessus?" (n. 44).

Entre la Luz en sí o imparticipada y la luz para nosotros o por participación, establece San Agustín una distinción total. No vemos a Dios, sino que vemos la verdad de las cosas a su luz. La verdad que conocemos y que es la regla de nuestros juicios no es Dios en persona, sino su reflejo, su impresión, su imagen en nuestro espíritu ${ }^{18}$.

6. San Agustín, para explicar el conocimiento verdadero, re-

18. Cfr. Ch. Boyer, Essais sur la doctrine de saint Augustin (Paris 1932) 93 . 
quiere siempre tres elementos. No basta un sujeto inteligente frente a un objeto inteligible, para que se dé conocimiento. Hace falta un tercer elemento: la luz.

Así como los ojos no pueden ver si no hay luz, así tampoco la razón, tanto teórica como práctica, si no es iluminada:

\begin{abstract}
"Sic mens nostra, quae est oculus animae, nisi veritatis lumine radietur, et ab illo qui illuminat nec iluminatur, mirabiliter illustretur, nec ad sapientiam, nec ad iustitiam poterit pervenire" ${ }^{19}$

"Sufficit sibi oculus ad non videndum, hoc est, ad tenebras; ad videndum vero lumine suo, non sibi sufficit, nisi illi extrinsecus adiutorium clari luminis praebeatur" 20.
\end{abstract}

Esta es la afirmación. Preguntemos ahora: ¿por qué? Si el sujeto es capaz de conocer y el objeto puede ser conocido, ¿qué necesidad hay de un tercer factor?

Recordemos ante todo que la teoría de la iluminación tiene por objeto explicar, no la formación de los conceptos (que son de algún modo innatos, para un pensador platónico), sino la afirmación de la verdad en el juicio. Escribe acertadamente R. Jolivet: "Ce qu'il s'agit d'expliquer, pour saint Augustin, ce n'est pas l'existence de l'idée abstraite et générale, mais l'existence et la formation de l'idée, vraie, c'est-à-dire du jugement par lequel nous attribuons à chaque chose une essence immuable et éternelle, telle qu'elle existe dans la pensée divine. Les textes son nombreux, chez saint Augustin, qui posent le problème sous cette forme particulière, et on ne les a souvent négligés que par la préoccupation de trouver chez lui une doctrine de la formation des concepts, qui ne s'y rencontre pas' ${ }^{21}$.

Pues bien, San Agustín ha visto que, en el conocimiento de la verdad, hay una característica que no se explica ni por objeto ni por el sujeto. El juicio verdadero no es una afirmación de hecho, sino de derecho. No dice es, sino debe ser ${ }^{22}$; no dice es ahora y aquí, sino es simplemente, sin determinación de tiempo ni lugar. El juicio verda-

19. In Ioan Evan 35,3 .

20. De gestis Pelagii III, 2,7.

21. Dieu soleil des esprits, 146.

22. Es sabida la importancia del verbo iudicare en la gnoseología agustiniana. 
dero es incondicionado, es (eterno", es necesario, en una palabra (que para un pensador platónico lo resume todo), es inmutable.

Ahora bien, el objeto es mudable y lo es también el sujeto, ambos están condicionados de muchos modos. $\mathrm{El}$ fundamento de la verdad no puede ser, por tanto, ni el objeto ni el sujeto. Hay que buscar más allá, una realidad inmutable, incondicionada, absoluta, que funde nuestro conocimiento de la verdad. Escribe M. Grabmann: "Una mirada de conjunto a los textos agustinianos causa la impresión de que el alma racional como tal no está todavía suficientemente equipada para ver las realidades inteligibles, sino que por un contacto con las rationes aeternae, con la luz divina increada (contacto que no implica sin embargo ninguna visión inmediata de Dios), una luz ilumina el alma y la hace capaz de ver las realidades inteligibles de alcanzar la verdad y la certeza y de conocer a Dios) ${ }^{23}$.

Finalmente, una vez admitida la necesidad de un Absoluto para explicar y fundar el absoluto que hay en todo conocimiento verdadero, preguntemos: ¿cómo, de qué modo interviene el Absoluto en nuestro conocimiento de la verdad?

Enunciaré, a modo de síntesis, las líneas generales de la teoría de la iluminación, que San Agustín define breve y substancialmente así: Illuminatio nostra, participatio Verbi est ${ }^{24}$.

Las ideas de todas las realidades posibles están en el Verbo, que es la Sabiduría (el Ars del Padre).

El Padre ha creado el mundo por el Verbo. Crear es iluminar o formar la materia informe (también creada), imprimiendo en ella la imagen de su idea en el Verbo.

Los seres espirituales, dotados de inteligencia (y de voluntad), reciben, además de esta iluminación física, una iluminación lógica (y ética), por la que pre-conocen (y pre-aman) en la memoria, las ideas del Verbo, según las cuales han sido hechas las cosas ${ }^{25}$.

Esto supuesto, es ya posible explicar y fundar el conocimiento de la verdad, partiendo siempre del principio platónico, que el conoci-

23. M. GRaBmanN, Der göttliche Grund menschlicher Wahrheitserkenntnis nach Augustinus und Thomas von Aquin (Müüster, 1924), 22.

24. De Trinitate IV, 2,4 .

25. Los textos correspondientes a estos últimos párrafos pueden ha- 
miento de lo desconocido sólo es posible por comparación con lo ya conocido.

En efecto, podemón conocer la verdad de las cosas: a) porque las cosas son verdaderas, es decir, son imágenes de sus ideas en el Verbo; y b) porque el espíritu conoce (pre-conoce) la verdad, es decir, el modelo, esas mismas ideas divinas.

Entonces la presencia de la imagen suscita el recuerdo del modelo, de la idea presente en la memoria por iluminación o por impresión. Conocemos porque reconocemos; reconocemos porque preconoce$\operatorname{mos}{ }^{26}$.

\section{Juan Pegueroles}

llarse en mis artículos: "El ser y el tiempo, la forma y la materia. Síntesis de la metafísica de San Agustín": Pensamiento, 28 (1972) 165-191; "La formación o iluminación en la metafísica de San Agustín": Espíritu 20 (1971) $134-149$.

26. "La notion de mémoire est vraiment au centre de la doctrine de l'illumination". R. JOLIVET, o.c., p. 173. 